Brian Milne MD, Kent Rogers MD, Frank Cervenko MD, Tomas Salerno MD

\title{
The haemodynamic effects of intraaortic versus intravenous administration of protamine for reversal of heparin in man
}

A recent report suggests that there may be advantages of intraaortic (IA) versus intravenous ( $I$ ) administration of protamine for reversal of heparin at the end of cardiopulmonary bypass. Because complete haemodynamic measurements were not performed in that study, we prospectively and randomily assessed the effects of protamine sulphate administered via either route. Patients were studied in the period immediately following cardiopulmonary bypass. Heparin, 300 units $\mathrm{Kg}^{-1}$, plus 150 units. $\mathrm{Kg}^{-1}$ when required, was administered to keep the activated cloting time $>400 \mathrm{sec}$. Protamine $3 \mathrm{mg} \cdot \mathrm{Kg}^{-1}$ was injected over $30 \mathrm{sec}$. intravenously in the $\mathrm{V}$ group ( $n$ $=5)$ and into the ascending aorta in the IA group $(n=5)$. There was a significant decrease in arterial blood pressure $(28.6$ per cent) from $109.2 \pm 5.6 \mathrm{mmHg}$ (S.E.) systolic to $78.0 \pm 9.0 \mathrm{mmHg}$ observed in the $I A$ group one minute post protanine, which returned to baseline by

Key words

BLOOD COAGULATION: heparin, protamine; BLOOD PRESSURE: drug effects.

From the Departments of Anaesthesia and Surgery, Queen's University, Kingston, Ontario.

Adtress correspondence to: Dr. B. Milme, Department of Anaesthesia, Kingston General Hospital, Kingston, Ontario K7L 2V7

Supported by Grants from the Ontario Heart Foundation and the Medical Research Council of Canada.

Presented in part at the Annual Meeting of the Canadian Anaesthetists' Society, Quebec City, 1982.
2.5 min (analysis of variance $p<0.05$ ). No significam hypotension was observed in the $N$ group. There was no significant change in heart rate, left airial pressure, central venous pressure, systemic vascular resistance or cardiac index with either IA ar IV protamine. In contrast to our recent study in pigs there was no significant change in pulmonary artery pressure, pulmonary vascular resistance or cardiac output with protamine. Results indicate that there are no haemodynamic benefits of IA vs $\mathrm{N}$ injection of proramine.

Recently it has been reported that the intraaortic (IA) administration of protamine sulphate for reversal of heparin post-cardiopulmonary bypass (CPB) is not accompanied by significant hypotension. ' However, no other haemodynamic parameters were measured, and no comparison was made between IA versus IV administration of protamine. A recent study from our laboratory ${ }^{2}$ demonstrated that there were no significant differences between IA and IV injection of protamine. Transient decreases in cardiac output $(\mathrm{CO})$ and marked increases in pulmonary artery pressure (PAP) and pulmonary vascular resistance (PVR) occurred when protamine was administered via either route in pigs. The objective of this study was to assess the haemodynamic effects of IV versus IA administration of protamine in man, and to determine whether one route of administration was safer than the other.

\section{Methods}

Ten patients were randomly selected for IA or IV 
TABLE I Profile of patients (mean \pm standard deviation)

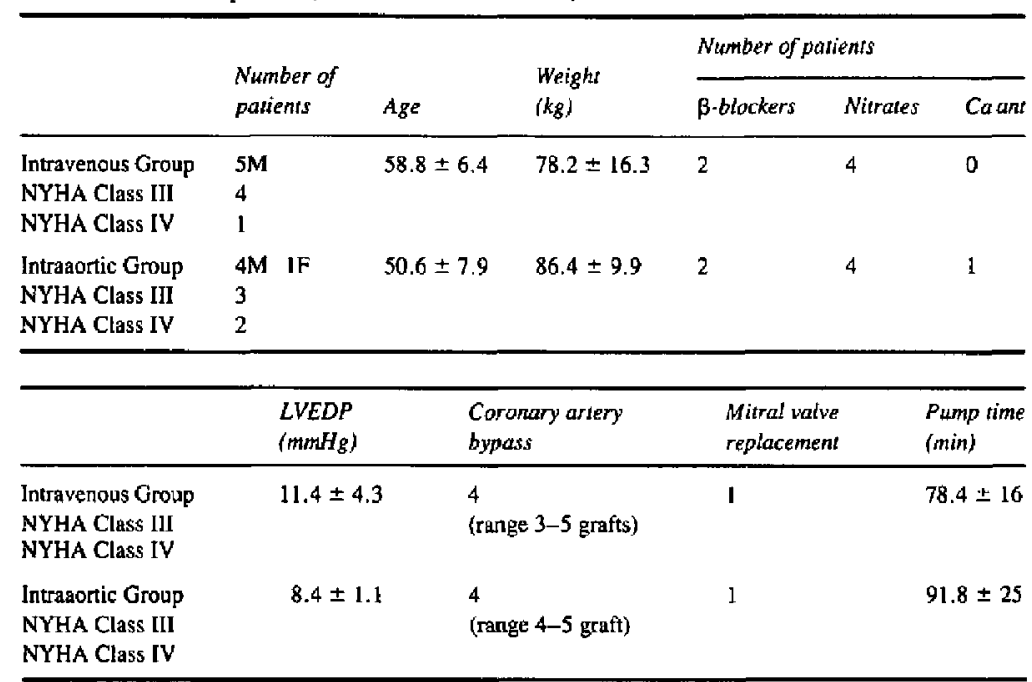

Legend: Ca ant, calcium antagonist. LVEDP, left ventricular end-diastolic pressare (mmHg). NYHA, New York Heart Association. M, Male. F, female.

administration of protamine sulphate and were studied during the period following CPB. Following the published report by Aris et al. ${ }^{1}$ we elected to adopt the clinical procedure of administering protamine by the intraaortic route, and had been doing this for several months without difficulty. It was then decided to do this comparative study, and it was felt that informed consent was not required. Four patients in each group had severe coronary artery disease requiring coronary artery bypass grafting and one patient in each group had mitral regurgitation necessitating mitral valve replacement (Table I). All patients were reported to have good myocardial function preoperatively as determined by cardiac catheterization and angiography.

Prior to induction of anaesthesia a 20-gauge cannula was inserted into the radial artery for continuous blood pressure monitoring. A thermodilution triple-lumen catheter 7F (Edwards Laboratories) was placed via the right internal jugular vein into the pulmonary artery and was used for determination of PAP (systolic, diastolic, mean and wedge) and $\mathrm{CO}$. Heart rate (HR) and electrocardiogram were continuously recorded. Anaesthesia was induced with fentanyl, diazepam, pancuronium and oxygen and maintained with fentanyl and oxygen.
The left atrial pressure (LAP) was recorded by a cannula inserted via a right superior pulmonary vein. Sodium heparin, all from the same lot, was given in an initial dose of 300 units $\cdot \mathrm{Kg}^{-1}$, followed by increments of 150 units $\mathrm{Kg}^{-1}$ to keep the activated clotting time greater than $400 \mathrm{sec}$. Following CPB and after stabilization with replacement of blood volume by intraaortic transfusion of the pump perfusate, control measurements of $\mathrm{HR}$, arterial pressure (AP), PAP, central venous pressure (CVP), LAP and CO (mean of 2 injections of $10 \mathrm{ml}$ cold five per cent dextrose, computed with an Edwards Laboratories Computer) were recorded.

During the study period no crystalloid, blood or vasoactive drugs were given and there was no manipulation of the heart. Protamine sulphate ( $3 \mathrm{mg} \cdot \mathrm{Kg}^{-1}$ ) was injected either by a peripheral vein (IV) or directly into the ascending aorta (IA) over $30 \mathrm{sec}$. Haemodynamics were then recorded at 1.0 , 2.5, 5.0 and $10 \mathrm{~min}$ following injection.

PVR, systemic vascular resistance (SVR) and cardiac index $(\mathrm{CI})$ were calculated using standard formulae. Control measurements between the IA and IV groups were compared for statistical significance using the Student's $t$ test for unpaired data. Data within each group were analyzed using analy- 
TABLE II Haemodynamic data for all patients pre- and post-protamine infusion (mean \pm S.E.)

\begin{tabular}{|c|c|c|c|c|c|c|c|}
\hline & & \multirow[b]{2}{*}{ Group } & \multirow[b]{2}{*}{ Baseline } & \multicolumn{4}{|c|}{ Post-protamine injection } \\
\hline & & & & $1.0 \mathrm{~min}$ & $2.5 \mathrm{~min}$ & $5.0 \mathrm{~min}$ & $10 \min$ \\
\hline & HR & IA & $90.6 \pm 5.3$ & $93.4 \pm 5.6$ & $89.6 \pm 6.7$ & $88.8 \pm 5.7$ & $91.2 \pm 5.6$ \\
\hline & & IV & $88.8 \pm 1.9$ & $89.8 \pm 2.3$ & $89.0 \pm 3.2$ & $90.6 \pm 3.6$ & $97.0 \pm 3.9$ \\
\hline \multirow[t]{2}{*}{ Systolic } & AP & LA & $109.2 \pm 5.6$ & $78.0 \pm 9.0^{*}$ & $105.8 \pm 5.9$ & $113.2 \pm 7.1$ & $114.4 \pm 9.2$ \\
\hline & & IV & $108.6 \pm 3.1$ & $110.6 \pm 8.7$ & $117.6 \pm 8.1$ & $121.0 \pm 6.2$ & $126.3 \pm 10.0$ \\
\hline \multirow[t]{2}{*}{ Diastolic } & AP & IA & $69.6 \pm 5.4$ & $51.2 \pm 5.9^{*}$ & $67.0 \pm 4.8$ & $73.2 \pm 4.6$ & $74.6 \pm 4.7$ \\
\hline & & IV & $62.8 \pm 3.5$ & $66.2 \pm 4.9$ & $67.4 \pm 5.2$ & $69.6 \pm 4.7$ & $78.8 \pm 4.3$ \\
\hline \multirow[t]{2}{*}{ Mean } & $\mathbf{A P}$ & LA & $83.0=5.2$ & $60.2 \pm 6.8^{*}$ & $79.8 \pm 4.6$ & $86.6 \pm 5.1$ & $87.8 \pm 5.4$ \\
\hline & & IV & $78.4 \pm 2.9$ & $80.8 \pm 6.1$ & $84.2 \pm 5.9$ & $87.2 \pm 4.8$ & $94.5 \pm 6.2$ \\
\hline \multirow[t]{2}{*}{ Systolic } & PAP & IA & $25.6 \pm 3.4$ & $23.4 \pm 0.5$ & $24.6 \pm 1.9$ & $22.0 \pm 2.3$ & $22.4 \pm 2.4$ \\
\hline & & IV & $30.6 \pm 3.5$ & $30.0 \pm 1.8$ & $34.6 \pm 4.9$ & $31.6 \pm 4.2$ & $29.0 \pm 2.4$ \\
\hline \multirow[t]{2}{*}{ Diastolic } & PAP & IA & $14.6 \pm 2.0$ & $15.0 \pm 1.4$ & $15.8 \pm 2.1$ & $12.4 \pm 1.7$ & $13.8 \pm 2.2$ \\
\hline & & IV & $18.2 \pm 1.6$ & $20.0 \pm 1.9$ & $20.7 \pm 2.7$ & $17.4 \pm 2.2$ & $18.0=2.0$ \\
\hline \multirow[t]{12}{*}{ Mean } & PAP & IA & $18.2 \pm 2.4$ & $17.8 \pm 1.1$ & $18.6 \pm 1.9$ & $15.6 \pm 1.8$ & $16.6 \pm 2.2$ \\
\hline & & IV & $22.0 \pm 2.0$ & $23.4 \pm 1.6$ & $24.6 \pm 2.7$ & $22.2 \pm 2.4$ & $21.8 \pm 4.0$ \\
\hline & LA & IA & $11.8 \pm 1.2$ & $11.4 \pm 1.2$ & $12.8 \pm 1.2$ & $11.6 \pm 0.9$ & $11.6 \pm 1.2$ \\
\hline & & IV & $10.2 \pm 1.4$ & $10.6 \pm 1.7$ & $10.8 \pm 1.8$ & $10.2 \pm 2.0$ & $9.5 \pm 1.7$ \\
\hline & CVP & IA & $10.4 \pm 1.9$ & $10.4 \pm 1.7$ & $10.8 \pm 2.1$ & $11.6 \pm 2.5$ & $13.4 \pm 2.5$ \\
\hline & & IV & $12.4 \pm 1.0$ & $14.3 \pm 2.4$ & $13.5 \pm 1.2$ & $14.0 \pm 1.8$ & $15.3=1.0$ \\
\hline & $\mathrm{CI}$ & IA & $2.79 \pm 0.29$ & $2.47 \pm 0.30$ & $2.73 \pm 0.23$ & $2.62 \pm 0.34$ & $2.29 \pm 0.25$ \\
\hline & & IV & $3.20 \pm 0.27$ & $3.33 \pm 0.20$ & $3.29 \pm 0.30$ & $2.92 \pm 0.36$ & $2.82 \pm 0.34$ \\
\hline & PVR & IA & $112.8 \pm 24.0$ & $112.8 \pm 22.15$ & $116.4 \pm 32.0$ & $72.2 \pm 23.71$ & $115.4 \pm 25.02$ \\
\hline & & IV & $174.4 \pm 53.26$ & $116.2 \pm 30.24$ & $189.8 \pm 56.11$ & $178.0 \pm 41.16$ & $206.8 \pm 50.47$ \\
\hline & SVR & IA & $1230 \pm 193.87$ & $810 \pm 122.52$ & $1058 \pm 182.41$ & $1327 \pm 216.80$ & $1374 \pm 220.0$ \\
\hline & & IV & $821 \pm 149.99$ & $773 \pm 143.00$ & $870 \pm 175,00$ & $1018 \pm 185.00$ & $1214 \pm 167.0$ \\
\hline
\end{tabular}

* = significant difference from baseline $(\mathrm{p}<0.05)$.

Legend: HR, heart rate (beats/min). IA, intraaortic. IV, intravenous. AP, arterial pressure (mmHg). LA, left atrial pressure. CVP, central venous pressure. $\mathrm{CI}$, cardiac index $\left(1-\mathrm{min}^{-1} \cdot \mathrm{m}^{-2}\right)$. PVR, pulmonary vascular resistance (dyne-sec $\left.\mathrm{cm}^{-5}\right) . \mathrm{SVR}$, systemic vascular resistance (dyne $\cdot \mathrm{sec}^{\prime} \mathrm{cm}^{-5}$ ). Systolic and diastclic pressure, $\mathrm{mmHg}$.

sis of variance. Significance was assessed at the $p<$ 0.05 level.

\section{Results}

Table II summarizes the results. There was no difference between the IA and IV groups in control haemodynamic measurements. There was a significant decrease in arterial blood pressure (28.6 per cent) from $109.2 \pm 5.6$ (S.E.) $\mathrm{mmHg}$ to $78.0 \pm$ $9.0 \mathrm{mmHg}$ observed in the IA group at 1.0 minute, which retumed to baseline by 2.5 minutes. No significant hypotension was observed in the IV group. There was no significant change in $\mathbf{H R}$, LAP, SVR, CVP or CI with either route of administration of protamine. In contrast to the study in pigs there was no change in PAP, PVR or CO.

\section{Discussion}

Injection of protamine for reversal of heparin at the end of CPB is not without hazards, and profound hypotension has been known to occur. ${ }^{3}$ Measures to counteract this haemodynamic effect include the slow administration of the drug ${ }^{4}$ volume expansion, calcium and/or vasopressor agents. ${ }^{5} \mathrm{~A}$ recent clinical report indicated that the administration of protamine into the ascending aorta did not result in significant hypotension. 'Investigation in our laboratory comparing IA versus IV administration of protamine in pigs failed to confirm that observation. ${ }^{2}$ In pigs, there was a decrease in $\mathrm{CO}$ and a marked increase in PAP and PVR with both IA and IV injection of protamine. Also, there was considerable individual variation in the arterial blood pressure response to protamine. When protamine alone was administered to the animal, without prior heparinization, no change in haemodynamics was observed.

This present clinical study failed to confirm that 
one route of administration (IA vs IV) is superior to the other in establishing stable haemodynamics. In fact there was a significant decrease in arterial blood pressure at 1.0 minute post IA infusion whereas no hypotension was observed in the IV group. Aris et al. ${ }^{\prime}$ observed hypotension with the IA injection of protamine which resolved by 2.2 minutes on the average. Unfortunately there was no comparison with the IV route of administration. However, there have been conflicting reports as to the haemodynamic effects of protamine. Some state that the drug has insignificant effects; ${ }^{1,6,7}$ others have observed a decrease in AP and an increase in PAP ${ }^{3}$ Postulated causes for the hypotension induced by protamine include a decrease in myocardial contractility, SVR, ionized calcium or release of vasoactive substances from the lung or platelets. ${ }^{5,8-12}$

In contrast to the study in pigs, ${ }^{2}$ the present study demonstrated no significant change in $\mathrm{CO}, \mathrm{PAP}$, or PVR. Since the response of the pulmonary circulation to protamine in pigs was so predictable and dramatic it would appear that species difference is probably the most important reason for its different effects in man. Thus, the rapid IA administration of protamine for reversal of heparin in man causes transient hypotension lasting less than 2.5 minutes. It may be prudent therefore to temporarily delay any therapeutic intervention such as vasopressors or volume replacement as recovery may be imminent. Intravenous injection of protamine appeared to have little effect on the circulation in the dose used in this study and reports of hypotension may be a result of individual sensitivity to the drug or different dosages.

Species difference is very important when assessing the effects of protamine. Further studies are necessary in order to fully understand the mechanism of action of the protamine-heparin complex, its effects on the circulation, and possible pharmacological manipulations that might make its use safer during open-heart surgery.

\section{References}

I Aris A, Solanes H, Bonnin JO, Garin R, Caralps $J M$. Intraaortic administration of protamine: Method for heparin neutralization after cardiopulmonary bypass. Cardiovasc Dis Bull Texas Heart Inst. 1981; 8: 23-8.

2 Rogers $K$, Milne B, Salerno TA. The hemodynamic effects of intraaortic versus intravenous administration of protamine for reversal of heparin in pigs. J Thorac Cardiovasc Surg. (In press.)

3 Jastrzebski I, Sykes MK, Wood DG. Cardiorespiratory effects of protamine after cardiopulmonary bypass in man. Thorax 1974; 29: 534-8.

4 Findlayson DC, Kaplan JA. Cardiopulmonary Bypass. In Cardiac Anesthesia. (ed.) Kaplan JA. New York, Grune and Stratton, 1979; pp. 393-440

5 Fadali MA, Papacostas CA, Duke JJ, Ledbetter $M$, Osbakken $M$. Cardiovascular depressant effect of protamine sulphate: Experimental study and clinical implications. Thorax 1976; 31: 320-3.

6 Conahan TJ, Andrews RW, MacVaugh $H$. Cardiovascular effects of protamine in man. Anesth Analg 1981; 60: 33-6.

7 Ching KS, Leong DS. Cardiopulmonary effects of protanine in man. Anesthesiology 1980; 53 : S116.

8 Radegran K, McAslan C. Circulatory and ventilatory effects of induced platelet aggregation and their inhibition by acetylsalicylic acid. Acta Anaesthesiol Scand 1972; 16: 76-84.

9 Goldman BS, Joisin J, Austin WG. Cardiovascular effects of protamine sulfate. Ann Thorac Surg 1969; 7: 459-71.

10 Iwatsuki N, Matsukawa S. Iwatsuki $K$. A weak negative inotropic effect of protamine sulfate upon the isolated canine heart muscle. Anesth Analg 1980; 59: 100-2.

11 Marin-Neto JA, Sykes MK, Marin JLB, Orchard $C$, Chakrabarti MK. Effects of heparin and protamine on left ventricular performance in the dog. Cardiovasc Res 1979; 13: 254-9.

12 Jones RM, Hill AB, Nahrwold ML, Tait AR. Effect of protamine on plasma ionized calcium in the dog. Can Anaesth Soc J 1982; 29: 65-7. 
Résumé

Une étude récente a suggéré qu'il pourrait être avantageuxd' administrer la protamine par voie intra-aortique à la fin de la circulation extra-corporelle. Cependant, celte étude ne comporte pas de mesures précises des conséquences hémodynamiques d'un tel procédé. Nous avons donc décidé d'étudier les effets cardiovasculaires du sulfate de protamine selon qu' il est administré par voie intra-veineuse (IV) ou intra-aortique (IA) et ceci de façon prospective et aleatoire.

Dix patients ont été étudiés immédiatement après le sevrage de la circulation extra-corporelle. Les patients avaiem reçu de l'héparine 300 unités $\mathrm{Kg}^{-1}$ plus 150 unites $\mathrm{Kg}^{-1}$ au besoin pour maintenir un temps de cangulation activé (ACT) plus grand que $400 \mathrm{sec}$. La protanine, $3 \mathrm{mg} \cdot \mathrm{Kg}^{-1}$, a été injectée en $30 \mathrm{sec}$. par voie intra-veineuse $(N=5)$ ou intra-aortique $(N=5)$. On a noté une minute après l'injection intra-aortique, une diminution significative de la pression artérielle (28.6 pour cent), la systolique passant de $109.2 \pm 5.6 \mathrm{mmHg}$ (ET) a $78 \pm 9 \mathrm{mmHg}$ et un retour aux valeurs de contrôle à 2.5 min. (analyse de variance $p<0.05$ ). Par contre, il $n^{*} y$ a pas eu d'hypotension significative dans le groupe $I V$. Dans les deux groupes, il n'y a pas eu de changement significatif de la frequence cardiaque, des pressions auriculaire gauche et veineuse centrale, de la résistance périphérique ou de l'index cardiaque.

Contrairement à notre étude récente chez le porc, il $n^{r} y$ a pas ets, associé da la protamine, de changement significatif dans la pression artérielle, la résistance vasculaire pulmonaire ou le débit cardiaque. Les résultais obtenus indiquent qu'il $n^{\prime}$ est pas avantageux $d$ 'administrer la protamine par voie intra-aortique plutôt que par voie intra-veineuse. 